\title{
Analysis of Physical Conditions of the Yogyakarta Special Region Beach Volley Ball Team in Preparation for PON XX Papua 2021
}

\author{
Fauzi Fauzi ${ }^{1, *}$ Danang Wicaksono ${ }^{1,}$ Nur Cholis Majid ${ }^{1}$ \\ ${ }^{I}$ Faculty of Sport Sciences, Universitas Negeri Yogyakarta, Yogyakarta, Indonesia \\ ${ }^{*}$ Corresponding author.Email: fauzi@uny.ac.id
}

\begin{abstract}
Beach volleyball is a team sport played in pairs with intermittent characteristics, namely with periods of play and rest where the intensity varies. The characteristics of the beach volleyball game require an athlete with the good physical condition. This study aims to show scientific data related to the physical condition of the DIY beach volleyball team. The method used is descriptive quantitative. DIY beach volleyball team athletes consisting of 8 people are the subjects of this study. Based on the results of the study, it was found that the data analysis carried out showed an average speed of 4.67 seconds and was included in the good category. The average flexibility score is $50.88 \mathrm{~cm}$ and is in the very good category. The average leg power score is $6.20 \mathrm{~m}$ for the right leg and $6.13 \mathrm{~m}$ for the left foot, both of which are in the poor category. The average arm power score is $8.63 \mathrm{~m}$ so it is included in the inadequate category. The average endurance score is $51.46 \mathrm{mls} / \mathrm{kg} / \mathrm{min}$ and is in a good category.
\end{abstract}

Keywords: Physical condition, Beach volley ball

\section{INTRODUCTION}

Beach volleyball is a team sport played in pairs with intermittent characteristics, namely with periods of play and rest where the intensity varies. Magalhães in their research conducted observations on the heart rate and blood lactate concentration of the athletes during the match [1]. The results show that in beach volleyball, the aerobic system is found to be more dominant where the condition is also dependent on the ATP-PC (anaerobic alactic) system. In addition, players can play in positions as blockers or defenders. This specialization is important because it determines the physical condition and strategy of the match [2]. An in-game analysis is a useful means of studying the state of the game to improve the quality of training for matches [3]. In beach volleyball, in-game analysis is usually used to determine indicators such as rally duration, rest time between rallies, total game time, total rest time, set duration, match duration, and rally per set [4]. This parameter has previously been examined in young elite players and professionals, but was not investigated if the competition phase affected game conditions.
Most studies on game profiles in sports have been conducted in senior high-performance competitions (World Championships, Olympics, etc.) [5]. In beach volleyball, studies conducted on men's games on the World Tour revealed that the average set duration is around 21-23 minutes, the number of rallies per set is around $39-40$, the total rest time and rally duration are 17 minutes, and 8,5 seconds [6]. In addition, the characteristics in the game may affect physical characteristics (eg the continuity of the duration of the rally increases the number of actions performed by the player; contacts, jumps, strokes, etc.) Studies conducted in men's games on the World Tour added that players performed an average of 100 jumps per set and six jumps per rally.

In games, athletes generally use jumps to perform various match actions. Examples of this are movements such as blocking, attacking, and some types of services often using jumps [7]. Jumping height is a determinant of the competitive level of athletes [8], similar to that observed in indoor volleyball. In this sense, the technique performed by the athlete will determine some aspects of physical behavior. Block is a movement made on the net to prevent the ball from passing through the field where 
players who perform $80 \%$ of the block technique during the match are considered blockers [6]. This position seems to dictate a higher number of jumps made by the blocker than any other defender [ie. [4].

Changing positions in the game is also known to influence the condition of athletes. For example, when the blocker serves, he needs to move to the net to make a block action or when he leaves the net and returns to the defensive position. This set of factors (jumps and displacements) indicates that there will be increased stress in athletes as seen from GPS and heart rate analysis [9]. Differences in testosterone levels and cortisol ratios will also be found in this regard [3]. In addition, the sand surface also affects the biomechanics and increases physiological responses [9].

In addition to the above factors, the quality of the opponent's game also has great relevance in determining the performance of the team in a player's game. Several situational variables (such as the quality of opponents) can have a marked effect on performance levels in sports [10]. In indoor volleyball, the quality of the opponent interacts with performance in defense and attack. A team in this case will show different offensive strategies according to their opponent. Apart from the effect of the displayed opponent's quality, this factor also affects the physical condition of the players in a team. For example, Blockers can make more jumps because they block every attack of a better quality opponent.

The factors in the beach volleyball game as described above will affect the physical condition of the athlete. Athletes must have the excellent physical condition to prepare themselves to face various factors that influence the game of volleyball. The physical condition consists of several components such as endurance, speed, strength, flexibility, and coordination. Some of these components must be possessed so that an athlete can be in his best performance. For this reason, it is necessary to know the biomotor condition or fitness profile possessed by an athlete, especially when facing the competition phase. This study aims to determine the physical condition by considering the phase of competition that will be faced by a team.

\section{METHODS}

This research was conducted in a quantitative descriptive manner where data were taken through measurements whose results could be presented through a description of the situation obtained from the object under study. The approach used in this research is a one shoot model approach. Data is collected through retrieval once and at a moment. The sample of this study was 8 athletes from the DIY beach volleyball team for PON consisting of 4 men and 4 women. The data taken are data related to speed, arm muscle power, flexibility, leg power, and endurance. The instruments used in this study were the $30 \mathrm{~m}$ sprint test to measure speed, shocken test to measure arm muscle strength, sit and reach test to measure flexibility, triple hop jumps to measure leg power, and beep test to measure endurance.

Data analysis to find the average so that the percentage can be found is carried out by the following formula Calculated Average (Mean). The mean is the number obtained by dividing the total value by the number of individuals.

$$
\overline{\mathrm{X}}=\frac{\Sigma x}{N}
$$

Description :

$$
\begin{array}{ll}
\overline{\mathrm{X}} & =\text { Average } \\
\sum \mathrm{x} & =\text { Total value X (Sample) } \\
\mathrm{N} & =\text { Total Samples }
\end{array}
$$

The percentage of categories can be obtained using the following formula (Sugiyono, 2011):

Percentage $\mathrm{X}=\frac{\sum x 1}{\sum x \text { total }} \times 100 \%$

Description :

Percentage $\mathrm{X}=$ Percentage

$\Sigma \mathrm{x} 1=$ Total Variables $\mathrm{x} 1$

$\Sigma \mathrm{x}$ Total $=$ Total Variables $\mathrm{x}$ total

\section{RESULTS}

The research results obtained from the research data carried out are described in this section. The descriptive data presented is data obtained from tests conducted on the DIY PON Beach Volleyball team consisting of 8 athletes. Measurement of the physical condition includes several test items, such as (1) speed test, (2) flexibility test, (3) leg muscle explosive power

\begin{tabular}{|c|c|c|c|c|c|c|c|c|}
\hline No. & 1. & 2. & 3. & 4. & 5. & 6. & 7. & 8. \\
\hline $\begin{array}{c}\text { Categor } \\
y\end{array}$ & $\frac{3}{D}$ & $\frac{3}{D}$ & $\frac{3}{\frac{3}{D}}$ & $\frac{3}{\frac{3}{D}}$ & $\begin{array}{l}\frac{T}{D} \\
\frac{D}{3} \\
\frac{Q}{D}\end{array}$ & $\begin{array}{l}\frac{T}{D} \\
\frac{D}{3} \\
\frac{D}{D} \\
\frac{D}{D}\end{array}$ & $\begin{array}{l}T \\
\frac{1}{3} \\
\frac{D}{D} \\
D\end{array}$ & $\begin{array}{l}\frac{T}{D} \\
\frac{D}{3} \\
\frac{D}{D}\end{array}$ \\
\hline $\begin{array}{c}\text { Speed } \\
\text { (second } \\
\text { ) }\end{array}$ & $\begin{array}{c}4,2 \\
7\end{array}$ & $\begin{array}{c}4,1 \\
6\end{array}$ & $\begin{array}{l}4, \\
2 \\
6\end{array}$ & $\begin{array}{c}4,3 \\
5\end{array}$ & 5,5 & $\begin{array}{c}4,7 \\
8\end{array}$ & 5,3 & $\begin{array}{c}4,7 \\
6\end{array}$ \\
\hline $\begin{array}{c}\text { Flexibilit } \\
\text { y (cm) }\end{array}$ & 50 & $\begin{array}{c}42, \\
5\end{array}$ & $\begin{array}{l}51 \\
, 5\end{array}$ & 54 & 50 & 55 & 51 & 53 \\
\hline $\begin{array}{l}\text { Power } \\
\text { of right } \\
\text { leg }(m)\end{array}$ & 7,4 & 7,5 & $\begin{array}{l}6, \\
5\end{array}$ & $\begin{array}{l}\text { Inju } \\
\text { ry }\end{array}$ & $\begin{array}{c}4,7 \\
6\end{array}$ & $\begin{array}{c}6,2 \\
5\end{array}$ & 5,55 & $\begin{array}{c}5,4 \\
6\end{array}$ \\
\hline Power & 7,5 & 7,1 & 5, & 4,11 & 5,3 & 5,4 & 7,57 & Inj \\
\hline
\end{tabular}
test, (4) arm power test, (5) endurance test.

Table 1. Test results of DIY beach volleyball team for PON 


\begin{tabular}{|c|c|c|c|c|c|c|c|c|}
\hline $\begin{array}{l}\text { of left } \\
\text { leg }(m)\end{array}$ & & 6 & 75 & & & 9 & & ury \\
\hline $\begin{array}{l}\text { Arm } \\
\text { power } \\
(\mathrm{m})\end{array}$ & 9,0 & 8,6 & $\begin{array}{l}8, \\
0\end{array}$ & 7,7 & 8,1 & 9,9 & 5,8 & $\begin{array}{c}11,9 \\
5\end{array}$ \\
\hline $\begin{array}{l}\text { Endura } \\
\text { nce } \\
\text { (mls/kg } \\
\text { /min) }\end{array}$ & $\begin{array}{c}57 \\
4\end{array}$ & $\begin{array}{c}62 \\
2\end{array}$ & $\begin{array}{l}5 \\
0 \\
8\end{array}$ & $\begin{array}{c}50, \\
5\end{array}$ & $\begin{array}{c}45, \\
5\end{array}$ & $\begin{array}{c}49, \\
3\end{array}$ & 45,5 & $\begin{array}{c}50, \\
5\end{array}$ \\
\hline
\end{tabular}

\subsection{Speed Test}

The results of the statistical analysis of the speed test of the DIY Beach Volleyball team for PON are presented in the following table:

Table 2. Statistical analysis of the speed test

\begin{tabular}{|c|c|c|c|}
\hline No. & Average & Min Result & Max Result \\
\hline 1 & 4,67 & 5,50 & 4,16 \\
\hline
\end{tabular}

\subsection{Flexibility Test}

The results of the statistical analysis of the flexibility test of the DIY Beach Volleyball team for PON are presented in the following table:

Table 3. Statistical analysis of the flexibility test

\begin{tabular}{|c|c|c|c|}
\hline No. & Average & Min Result & Max Result \\
\hline 1 & 50,88 & 42,50 & 55,00 \\
\hline
\end{tabular}

The data obtained from the flexibility test using sit and reach on 8 athletes shows that the highest score is $55 \mathrm{~cm}$ and the lowest score is $42.5 \mathrm{~cm}$. The average flexibility score of the DIY PON Beach Volleyball team is $50.88 \mathrm{~cm}$.

\subsection{Leg Power Test}

The results of the statistical analysis of the leg power test of the DIY Beach Volleyball team for PON are presented in the following table:

Table 4. Statistical analysis of the leg power test

\begin{tabular}{|c|c|c|c|}
\hline No. & Average & Min Result & Max Result \\
\hline Right leg & 6,20 & 4,76 & 7,50 \\
\hline Left leg & 6,13 & 4,11 & 7,57 \\
\hline
\end{tabular}

The data from the leg power test were obtained using a triple jump performed by 8 athletes. The test results show that the highest score obtained is with a distance of $7.5 \mathrm{~m}$ for the right foot and $7.57 \mathrm{~m}$ for the left foot, while the lowest score is obtained with a distance of $4.7 \mathrm{~m}$ for the right foot and $4.11 \mathrm{~m}$ for the left foot. The average leg power test score for the DIY Beach Volleyball team for PON was $6.20 \mathrm{~m}$ for the right foot and $6.13 \mathrm{~m}$ for the left foot. Based on the triple jump test conducted, it was found that athletes could not participate due to injury, where 1 athlete did not take the triple jump for the right leg and 1 athlete for the left foot.

\subsection{Arm Power Test}

The results of the statistical analysis of the speed test of the DIY Beach Volleyball team for PON are presented in the following table:

Table 5. Statistical analysis of the arm power test

\begin{tabular}{|c|c|c|c|}
\hline No. & Average & Min Result & Max Result \\
\hline 1 & 8,63 & 5,80 & 11,95 \\
\hline
\end{tabular}

The data obtained from the arm power test using the shocken test of 8 athletes shows that the highest score is obtained at a distance of $11.95 \mathrm{~m}$, while the lowest score is $5.80 \mathrm{~m}$. The average arm power score of the DIY Beach Volleyball team for PON, in this case, is $8.63 \mathrm{~m}$.

\subsection{Endurance Test}

The results of the statistical analysis of the endurance test of the DIY Beach Volleyball team for PON are presented in the following table:

Table 6. Statistical analysis of endurance test

\begin{tabular}{|c|c|c|c|}
\hline No. & Average & Min Result & Max Result \\
\hline 1 & 51,46 & 45,50 & 62,20 \\
\hline
\end{tabular}

Data related to endurance were obtained using the MFT test conducted on 8 athletes showing the highest score of $62.20 \mathrm{mls} / \mathrm{kg} / \mathrm{min}$ and the lowest score of $45.50 \mathrm{mls} / \mathrm{kg} / \mathrm{min}$. The average endurance score of the DIY Beach Volleyball team for PON is 51.46 $\mathrm{mls} / \mathrm{kg} / \mathrm{min}$. 


\section{DISCUSSION}

The results of the data analysis will then be compared to the norms in each test. The following is a discussion of the athlete's physical condition based on the measurement results in each test.

\subsection{Speed}

The data obtained from the speed test owned by the beach volleyball players of the DIY PON team, in this case, were compared to the $30 \mathrm{~m}$ sprint test value norm [11]

Table 7. Speed norm

\begin{tabular}{|c|c|c|c|}
\hline No & Male Score & Norm & Female Score \\
\hline 1. & $3.58-3.91$ & Excellent & $4.06-4.50$ \\
\hline 2. & $3.92-4.34$ & Good & $4.51-4.96$ \\
\hline 3. & $4.35-4.72$ & Medium & $4.97-5.40$ \\
\hline 4. & $4.73-5.11$ & Fair & $5.41-5.86$ \\
\hline 5. & $5.12-5.50$ & Poor & $5.87-6.30$ \\
\hline
\end{tabular}

The data description of the results of the speed test calculation is presented in the following table:

Table 8. Percentage of the $30 \mathrm{~m}$ sprint test category

\begin{tabular}{|c|c|c|c|}
\hline No & Norm & Frequency & Percentage \\
\hline 1. & Excellent & & \\
\hline 2. & Good & 5 & $62,5 \%$ \\
\hline 3. & Medium & 2 & $25 \%$ \\
\hline 4. & Fair & 1 & $12,5 \%$ \\
\hline 5. & Poor & & \\
\hline
\end{tabular}

The data above shows that $62.5 \%$ of the speed of the DIY beach volleyball team for PON is in a good category, $25 \%$ is in the medium category, and $12.5 \%$ is in the inadequate category. The percentage of these categories can be seen in the following diagram table:

\section{Percentage Category of Sprint $30 \mathrm{~m}$ Test}

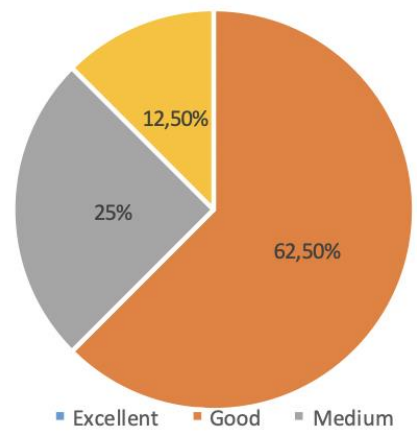

Figure 1 Category diagram of the $30 \mathrm{~m}$ sprint test of DIY beach volleyball team for PON

The data above shows that the speed possessed by the athletes of the DIY beach volleyball team for PON needs to be increased considering that speed is one of the important aspects needed. Speed is the ability to move in a short time and is a measure of the distance traveled per unit time, usually in minutes, seconds, or a quantity scale [12]. In the game of beach volleyball, players need speed to move from one point to another.

One of the physical components that also affect the down-passing technique component is agility. It is known that agility is the ability to be able to change direction from one direction to another quickly. Thus, agility will also be influenced by the speed possessed by the athlete. Therefore, good speed is important for beach volleyball athletes to have.

\subsection{Flexibility}

Based on the findings obtained from this study, the flexibility data possessed by DIY beach volleyball players for the PON will be compared with the norm of sit and reach test scores (Irawan, 2014)

Table 9. Flexibility norm

\begin{tabular}{|c|c|c|c|}
\hline No & $\begin{array}{c}\text { Male } \\
\text { Score }\end{array}$ & Norm & Female Score \\
\hline 1. & $>41$ & Excellent & $>46$ \\
\hline 2. & $31-40$ & Good & $35-45$ \\
\hline 3. & $21-30$ & Medium & $26-34$ \\
\hline 4. & $11-20$ & Fair & $16-25$ \\
\hline 5. & $<10$ & Poor & $<15$ \\
\hline
\end{tabular}

The data description of the results of the flexibility test calculation is presented in the following:

Table 10. Percentage categories of sit and reach test

\begin{tabular}{|c|c|c|c|}
\hline No & Norm & Frequency & Percentage \\
\hline 1. & Excellent & 8 & $100 \%$ \\
\hline 2. & Good & & \\
\hline 3. & Medium & & \\
\hline 4. & Fair & & \\
\hline 5. & Poor & & \\
\hline
\end{tabular}

The data above shows that $100 \%$ of the flexibility possessed by the DIY beach volleyball team for PON is in the very good category. In the form of a diagram, the results are presented in the form of percentage categories as follows 


\section{Percentage Category of Sit and Reach Test}

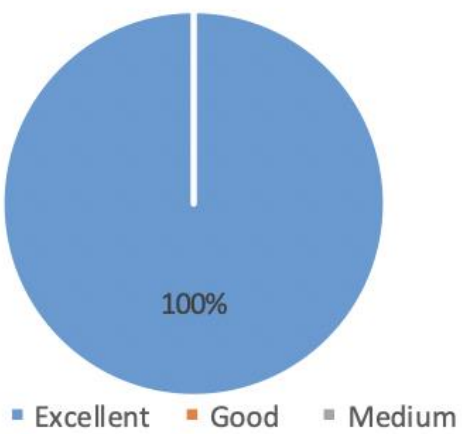

Figure 2 Sit and reach test category diagram of DIY beach volleyball team for PON

The flexibility possessed by the athletes of the DIY beach volleyball team for PON is included in the excellent category. This will certainly support the performance of the athletes to achieve optimal performance. Flexibility needs to be possessed by every player in various sports to avoid injury while increasing ability (Venghela, 2013). Flexibility is also needed in volleyball to support taking the ball and reaching farther athletes, especially when players defend and reach when do smash. Beach volleyball games thus need to be supported with good flexibility. Flexibility can be trained, one of which is by doing continuous stretching movements.

\subsection{Leg Power}

The results of the data obtained related to the measurement of leg power possessed by beach volleyball players on the DIY team for PON compared to the Triple Jump value norm (Lumintuarso, 2001):

Table 11. Leg power norms

\begin{tabular}{|c|c|c|c|c|c|}
\hline \multirow{2}{*}{ No } & \multirow{2}{*}{ Norm } & \multicolumn{2}{|c|}{ Right leg } & \multicolumn{2}{c|}{ Left leg } \\
\cline { 3 - 6 } & & $\begin{array}{c}\text { Male } \\
\text { Score }\end{array}$ & $\begin{array}{c}\text { Female } \\
\text { Score }\end{array}$ & $\begin{array}{c}\text { Male } \\
\text { Score }\end{array}$ & $\begin{array}{c}\text { Female } \\
\text { Score }\end{array}$ \\
\hline 1. & Excellent & $>9,40 \mathrm{~m}$ & $>8,09 \mathrm{~m}$ & $>9,34 \mathrm{~m}$ & $>8,05 \mathrm{~m}$ \\
\hline \multirow{2}{*}{2.} & \multirow{2}{*}{ Good } & $8,23-$ & $8,09-$ & $8,18-$ & $8,05-$ \\
& & $9,40 \mathrm{~m}$ & $7,18 \mathrm{~m}$ & $9,34 \mathrm{~m}$ & $7,16 \mathrm{~m}$ \\
\hline \multirow{2}{*}{3.} & \multirow{2}{*}{ Medium } & $8,23-$ & $7,18-$ & $8,18-$ & $7,16-$ \\
& & $7,65 \mathrm{~m}$ & $6,73 \mathrm{~m}$ & $7,60 \mathrm{~m}$ & $6,71 \mathrm{~m}$ \\
\hline \multirow{2}{*}{4.} & \multirow{2}{*}{ Fair } & $7,65-$ & $6,73-$ & $7,60-$ & $6,71-$ \\
& & $5,90 \mathrm{~m}$ & $5,36 \mathrm{~m}$ & $5,87 \mathrm{~m}$ & $5,37 \mathrm{~m}$ \\
\hline 5. & Poor & $<5,90 \mathrm{~m}$ & $<5,36 \mathrm{~m}$ & $<5,87 \mathrm{~m}$ & $<5,37 \mathrm{~m}$ \\
\hline
\end{tabular}

Data related to the description of the calculation results of the leg power test are presented in the following table:

Table 12. Triple jump test category percentage

\begin{tabular}{|c|c|c|c|c|c|}
\hline \multirow{2}{*}{ No } & \multirow{2}{*}{ Norm } & \multicolumn{2}{|c|}{ Frequency } & \multicolumn{2}{c|}{ Percentage } \\
\cline { 3 - 6 } & & Right & Left & Right & Left \\
\hline 1. & Excellent & & & & \\
\hline 2. & Good & & 2 & & $28,5 \%$ \\
\hline 3. & Medium & & 1 & & $14,25 \%$ \\
\hline 4. & Fair & 6 & 1 & $85,75 \%$ & $14,25 \%$ \\
\hline 5. & Poor & 1 & 3 & $14,25 \%$ & $43 \%$ \\
\hline
\end{tabular}

The data above shows that $85.75 \%$ of the power of the right leg owned by the DIY PON beach volleyball team is in the inadequate category and $14.25 \%$ in the poor category. Meanwhile, the power of the left leg shows $28.5 \%$ so that it is in a good category, $14.25 \%$ in the moderate category, $14.25 \%$ in the inadequate category, and $43 \%$ in the poor category. In the form of a diagram, the percentage of categories is presented as follows:

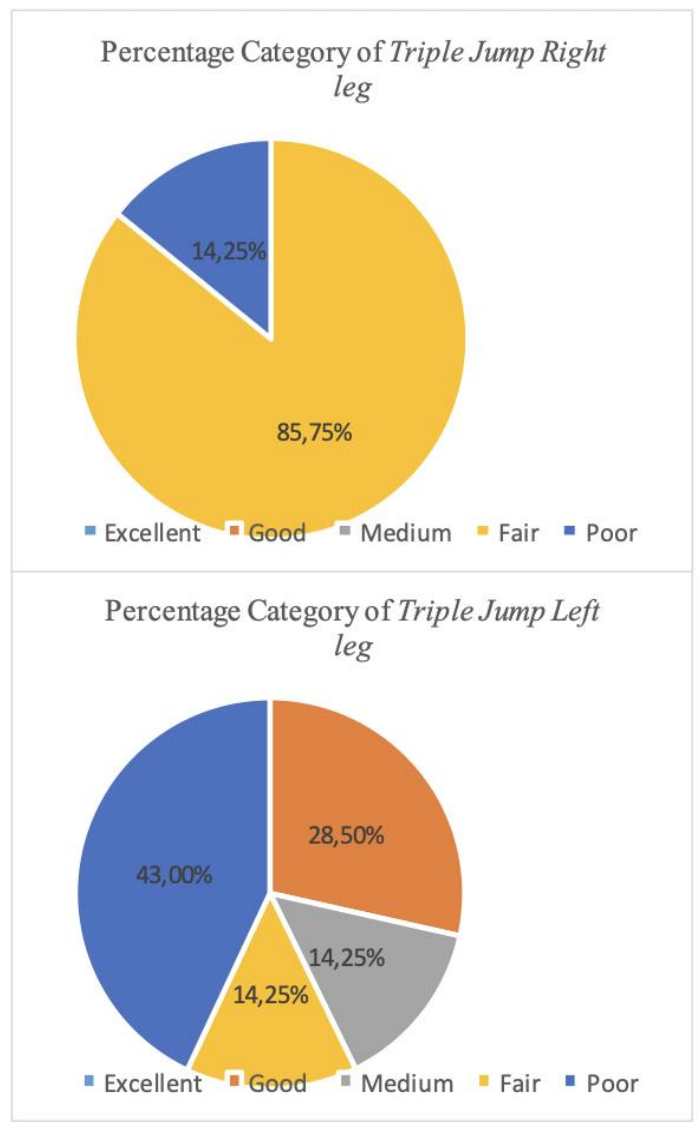

Figure 3. Category diagram on triple jump test of the DIY beach volleyball team for PON 
Knowing the data obtained as presented above, it can be concluded that the leg power level of the athletes of the DIY beach volleyball team for PON needs to be increased. This is because the jumps are possessed by athletes, both in smashing and blocking, depending on the power of the legs they have. The better the leg power, the more optimal the jump height will be. In every jump, the leg muscles are the foundation and support in pushing so that the body can be lifted and floated in the air (Hidayat, Saichudin, and Kinanti, 2018). In addition to this, leg muscle power is also very important considering the playing field in beach volleyball is made of sand which requires extra energy to move. This is different from the situation in indoor volleyball where the court is not made of sand. Although it was found that athletes were still in the injury recovery stage, the data presented showed the need for efforts to increase leg power for athletes from the DIY beach volleyball team for PON with various methods such as weight training or plyometric exercises.

\subsection{Arm Power}

The results of the analysis of the data obtained regarding the arm power possessed by the beach volleyball players of the DIY team for PON in this study will be compared with the norms of the Shocken Test score (Lumintuarso, 2001):

Table 13. Arm power norms

\begin{tabular}{|c|c|c|c|}
\hline No & Male & Status & Female \\
\hline 1. & $>14,41 \mathrm{~m}$ & Excellent & $>11,19 \mathrm{~m}$ \\
\hline 2. & $11,91-14,41 \mathrm{~m}$ & Good & $11,19-9,44 \mathrm{~m}$ \\
\hline 3. & $11,91-10,66 \mathrm{~m}$ & Medium & $9,44-8,56 \mathrm{~m}$ \\
\hline 4. & $10,66-6,91 \mathrm{~m}$ & Fair & $8,56-5,93 \mathrm{~m}$ \\
\hline 5. & $<6,91 \mathrm{~m}$ & Poor & $<5,93 \mathrm{~m}$ \\
\hline
\end{tabular}

The data description of the calculation results of the arm power test is presented in the following table:

Table 14. Percentage of shocken test category

\begin{tabular}{|c|c|c|c|}
\hline No & Norm & Frequency & Percentage \\
\hline 1. & Excellent & 1 & $12,5 \%$ \\
\hline 2. & Good & 1 & $12,5 \%$ \\
\hline 3. & Medium & & \\
\hline 4. & Fair & 5 & $62,5 \%$ \\
\hline 5. & Poor & 1 & $12,5 \%$ \\
\hline
\end{tabular}

The data above shows that $12.5 \%$ of the arm power owned by the DIY beach volleyball team for PON is in the excellent category, $12.5 \%$ is in a good category, $62.5 \%$ is in the inadequate category, and $12.5 \%$ is in the poor category. The percentage of these categories is presented in the form of a diagram as follows:

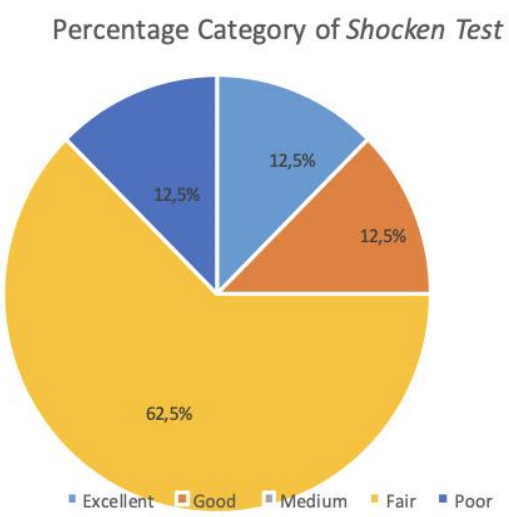

Figure 4 Shocken test category diagram of DIY beach volleyball team for PON

Beach volleyball game is performed by moving the ball using the hand as the dominant body part used. The ability to push the ball will be greatly influenced by the power of the arm. The data shows that $62.5 \%$ of athletes in the DIY beach volleyball team for PON have arm power in the inadequate category and $12.5 \%$ in the poor category. Therefore, more intense training is needed to increase the arm power they have. One of the various kinds of techniques that can be used is the smash technique. This technique is very dependent on leg power, flexibility, and arm power (Oktariana and Handoyo, 2020).

\subsection{Durability}

The data obtained related to the endurance possessed by beach volleyball players in the DIY team for PON compared to the Vo2Max value norm (Harsuki, 2003:

Table 15. VO2Max norm

\begin{tabular}{|c|c|c|c|}
\hline No & Male & Status & Female \\
\hline 1. & $>61,00$ & Excellent & $>54,30$ \\
\hline 2. & $55,10-60,90$ & Good & $49,30-54,20$ \\
\hline 3. & $49,20-55,00$ & Medium & $44,20-49,20$ \\
\hline 4. & $43,30-49,10$ & Fair & $39,20-44,10$ \\
\hline 5. & $<43,20$ & Poor & $<39,10$ \\
\hline
\end{tabular}


The data description of the results of the endurance test calculation is presented in the following table:

Table 16. Category percentage of vo $2 \max$

\begin{tabular}{|c|c|c|c|}
\hline No & Norm & Frequency & Percentage \\
\hline 1. & Excellent & 1 & $12,5 \%$ \\
\hline 2. & Good & 3 & $37,5 \%$ \\
\hline 3. & Medium & 4 & $50 \%$ \\
\hline 4. & Fair & & \\
\hline 5. & Poor & & \\
\hline
\end{tabular}

The data above shows that $12.5 \%$ of the endurance of the DIY PON beach volleyball team is in the excellent category, $37.5 \%$ in the good category, and $50 \%$ in the medium category. The percentage of these categories is presented in the following diagram:

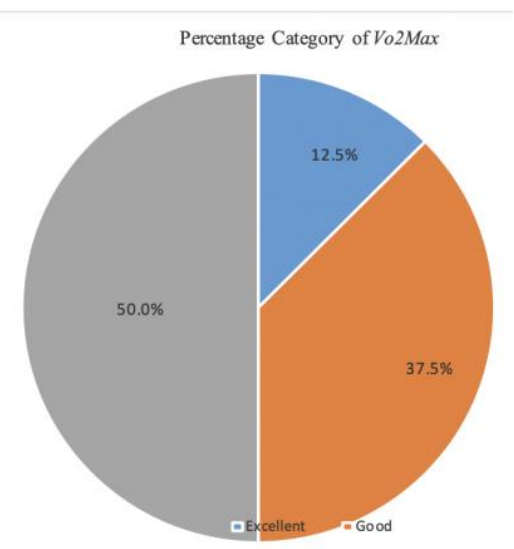

Figure 5 Vo2Max category diagram of DIY beach volleyball team for PON

Referring to the results of the VO2Max test data of the DIY Beach volleyball team for PON, it was assumed that the endurance capability needs to be further improved considering that this component is very influential on the performance of the sand volleyball match. In a study conducted on men's games on the World Tour related to beach volleyball, it showed that the average set duration found was around 21-23 minutes, the number of rallies per set was about $39-40$, the total rest time and rally duration were 17 minutes and 8 minutes. .5 seconds (Giatsis et al., 2005; Palao et al., 2012). In addition, the characteristics in the game were also found to affect physical characteristics (eg the continuity of the duration of the rally increases the number of actions performed by the player; contacts, jumps, punches, etc.) (Giatsis and Papadopoulou, 2003). Considering these conditions, the endurance of an athlete is required to always be in excellent condition so that performance in the game can be maintained.

\section{CONCLUSION}

Based on the results of research that has been carried out on the DIY volleyball athlete test for PON, the results conclude that the highest score on the speed test is 4.16 seconds and the lowest score is 5.50 seconds. The average speed score of the DIY Beach Volleyball for the PON team is 4.67 seconds which is included in the good category. Analysis of the data on the flexibility test results showed that the highest score obtained was $55 \mathrm{~cm}$ with the lowest score of $42.5 \mathrm{~cm}$. The average flexibility score of the DIY Beach Volleyball team for PON is $50.88 \mathrm{~cm}$ and is in the excellent category. Data analysis on the leg power test showed a distance of $7.5 \mathrm{~m}$ as the highest score for the right foot and $7.57 \mathrm{~m}$ for the left foot, while the lowest score obtained was $4.7 \mathrm{~m}$ for the right foot and $4.11 \mathrm{~m}$ for the left foot. The average leg power score of the DIY Beach volleyball team for PON is $6.20 \mathrm{~m}$ for the right foot and $6.13 \mathrm{~m}$ for the left foot and is included in the poor category. Data analysis on the arm power test showed that the highest score was obtained at a distance of $11.95 \mathrm{~m}$ and the lowest score was obtained at a distance of $5.80 \mathrm{~m}$. The average arm power score of the DIY Beach Volleyball team for PON is $8.63 \mathrm{~m}$ and is included in the poor category. Data analysis on endurance showed the highest score was $62.20 \mathrm{mls} / \mathrm{kg} / \mathrm{min}$ and the lowest score was 45.50 $\mathrm{mls} / \mathrm{kg} / \mathrm{min}$. The average endurance score of the DIY Beach Volleyball team for PON is $51.46 \mathrm{mls} / \mathrm{kg} / \mathrm{min}$ and is in a good category.

The data obtained from the measurements of the DIY Beach Volleyball team for PON can be used as a reference in determining the training program that needs to be implemented and also as material for future evaluations. Seeing the ability of arm power and leg power which is still in the poor category, it is suggested that this point can be more focused for trainers. The exercises that are made are also recommended to be arranged by considering the appropriate training variables.

\section{REFERENCES}

[1] Magalhães, J., Inácio, M., Oliveira, E., Ribeiro, J. C., \& Ascensão, A. (2011). Physiological and neuromuscular impact of beach-volleyball with reference to fatigue and recovery. Journal of Sports Medicine and Physical Fitness, 51(1), 66-73.

[2] Jimenez-Olmedo, J. M., Pueo, B., \& Penichet-Tomas, A. (2016). Defensive systems during the Men's European University Beach Volleyball Championship. Journal of Physical Education and Sport, 16(3), 945-950. https://doi.org/10.7752/jpes.2016.03149Graham, G., Shirley, H., Parker. (2010). Children moving, a reflective approach to 
teaching physical education. New York: McGraw Hill Companies.

[3] Costa, Y. P., Vecchio, F. B. Del, Lima, J. M., Castellano, L. R. C., \& Atista, G. R. (2020). Beach Volleyball: Temporal Analysis and Endocrine Responses of National Athletes. Journal Motricidade, 16(4), 379-385. https://doi.org/https://doi.org/10.6063/motricidade.20377natal i

[4] Lopez-Martinez, A. B., Palao, J. M., Ortega, E., \& Garcia-deAlcaraz, A. (2020). Efficacy and manner of execution of the serve in top-level women's beach volleyball players. Journal of Physical Education, 31,1-9. https://doi.org/10.4025/jphyseduc.v31i1.3142

[5] Alves, R., Robles, C., Pasqua, L. , Artioli, G., Roschel, H., Solis, M., Tobias, G., Klansener, C., Bertuzzi, R., Franchini, E., Junior, A. and Gualano, B. (2012) Anthropometric, physiological, performance, and nutritional profile of the Brazil National Canoe Polo Team. Journal of Sports Sciences, 30(3), 305-311Zhou, J. (2015). The value of music in children's enlightenment education. Open Journal of Social Sciens

[6] Giatsis, G., Zetou, E. and Tzetzis, G. (2005) The effect of rule changes for the scoring system on the duration of the beach volleyball game. Journal of Human Movement Studies, 48(1), 15-23.
[7] Busca, B., Moras, G., Javier, P. A., \& Rodriguez-Jimenez, S. (2012). The influence of serve characteristics on performance in men's and women's high-standard beach volleyball. Journal of Sports Sciences, 30(3), 269-272. https://doi.org/10.1080/02640414.2011.635309

[8] Batista, G. R., Araujo, R. F. de;, \& Guerra, R. O. (2008). Comparison between vertical jumps of high performance athletes on the Brazilian men's beach volleyball team. Journal of Sports Medicine and Physical Fitness, 48, 172176.

https://doi.org/10.1002/14651858.CD005954.pub2.Fundings

[9] Binnie, M. J., Dawson, B., Pinnington, H., Landers, G., \& Peeling, P. (2013). Part 2: Effect of training surface on acute physiological responses after sport-specific training. Journal of Strength and Conditioning Research, 27(4), 1057-1066. https://doi.org/10.1519/JSC.0b013e3182651d63

[10] Lago, C. (2009) The influence of match location, quality of opposition, and match status on possession strategies in professional association football. Journal of Sports Sciences, 27(13), 1463- 1469

[11] P Fenanlampir dan Faruq. (2015). Tes dan Pengukuran dalam Olahraga. Yogyakarta ocial Science, Education and Humanities Research Volume 278.

[12] Budiwanto. (2004). Kebugaran Jasmani Atlet. Semarang: Depdikbud 